\title{
Multiple Unit Particle Systems (MUPS), a Versatile Strategy for Controlled Drug Delivery: Focus on Formulation and Process Concerns
}

Kallakunta VR, Sarabu S and Tiwari RV*

Department of Pharmaceutics and Drug Delivery, School of Pharmacy, The University of Mississippi, University, Mississippi 38677, USA

\begin{abstract}
In oral drug delivery modified release dosage forms (MRD) plays an important role in regulating the drug delivery to improve the quality of therapy. One excellent technique to formulate MRDs is multiple unit particle systems (MUPS), where the dosage form is distributed over multiple units rather than a single unit. This unique feature of MUPS makes them a suitable candidate for the delivery of different types of drug molecules for a variety of therapeutic purposes. The current techniques like fluidized bed granulation and, extrusion and spheronization are promising in maintaining uniformity of dosage form and successful drug delivery at the desired site or maintaining the desired time profile of drug delivery. Apart from formulation strategies more focus is required in process optimization and scale-up issues to broaden the range of application of MUPS to different drug candidates and drug delivery systems.
\end{abstract}

Keywords: Multiple unit particle systems (MUPS); Granulation; Bioavailability; Pellets

\section{Introduction}

In oral drug delivery modified release dosage forms (MRD) are the well suited option for controlled drug release in gastro-intestinal tract (GIT) instead of the conventional immediate release dosage forms (IRD). The MRDs are meant for the altering drug release and absorption with an intention to deliver the drug to different regions of GIT or for timely release of the dose. These dosage forms also help in maintaining the required plasma level of the drug over a long period of time. A simple way of formulating MRDs is multiple unit particle systems (MUPS) which contains pellets and all the units are integrated to form a single unit. MUPS may exist as pellets, powders, crystals, nonpareil sugar spheres, mini-tablets, coated particles etc. [1]. The particle size of less than $2 \mathrm{~mm}$ facilitates uniform drug absorption of the drug over the large surface area in GIT and more uniform drug absorption profile is assured compared to conventional unit dosage forms. This kind of particular distribution of dosage form assures more consistency in bioavailability by avoiding the problem of dose dumping [2]. These MUPS can be formulated into commonly used dosage forms like tablets and capsules, which makes them more economical and stable in terms of shelf life of the final dosage form [3]. The type of coating process required for MUPS can be done generally by using a fluidized bed coaster where the initial drug coat will be performed on pellets followed by further functional coatings depending on the formulation of dosage forms. Figure 1 represents a MUPS based tablet in which MUPS are admixed with other excipients and compressed into a tablet. Generally, MUPS are divided into 2 types of systems one is comprised of coated pellets and the other one is with uncoated pellets. The coated pellets will be acting as a reservoir system and uncoated pellets follow a general matrix pattern. In both cases, excipients should be separated

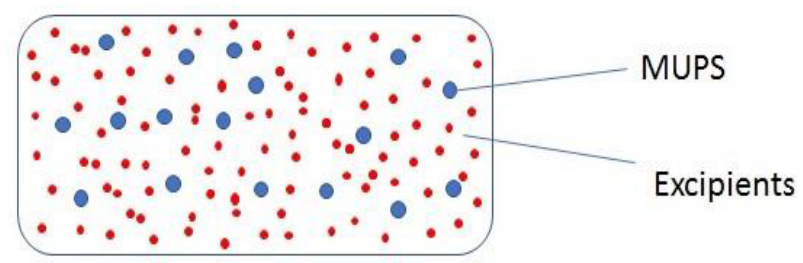

Figure 1: A general representation of MUPS tablet. from particular systems and should not interfere with the functionality of particles.

a) Coated pellets: Basically the coated particles are prepared by coating the required polymer on the spheres in a layer wise manner. The functionality of the dosage form depends on the type of functional coating on pellets (Figure 2). For e.g. Surelease ${ }^{\bullet}$ (Ethyl cellulose dispersion with $25 \%$ solid content for sustained release), Eudragit $\mathrm{EPO}^{\circ}$ (methacrylic based polymer soluble above $\mathrm{pH}$ 5) [4].

b) Uncoated pellets: These pellets are usually produced by extrusion and spheronization process and the behavior of matrix depend on the excipients incorporated. Waxes like glyceryl behenate or agents like xanthum gum can be incorporated in the pellet matrix depending on the desired drug release profile $[5,6]$.

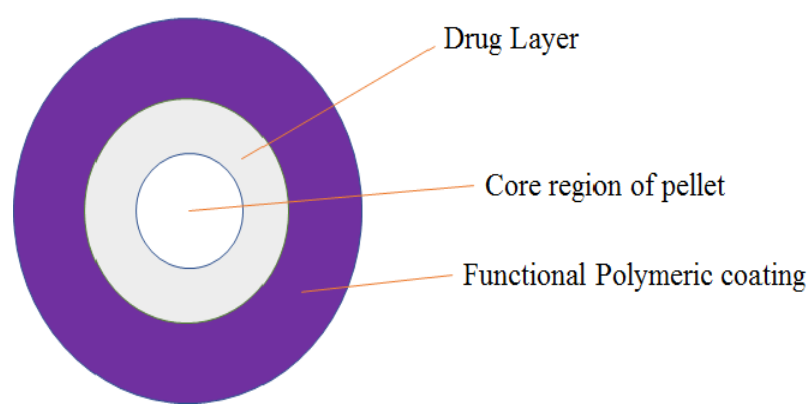

Figure 2: Schematic representation of different layers of a single unit in MUPS.

*Corresonding author: Tiwari RV, Department of Pharmaceutics and Drug Delivery, School of Pharmacy, The University of Mississippi, University, Mississipp 38677, USA, Tel: +1 662-915-7211; E-mail: roshanvt@gmail.com

Received February 27, 2017; Accepted March 10, 2017; Published March 14 2017

Citation: Kallakunta VR, Sarabu S, Tiwari RV (2017) Multiple Unit Particle Systems (MUPS), a Versatile Strategy for Controlled Drug Delivery: Focus on Formulation and Process Concerns. J Formul Sci Bioavailab 1: 106.

Copyright: @ 2017 Kallakunta VR, et al. This is an open-access article distributed under the terms of the Creative Commons Attribution License, which permits unrestricted use, distribution, and reproduction in any medium, provided the original author and source are credited. 


\section{Applications of MUPS in different drug delivery systems}

MUPS is a versatile technology for preparation of different types of dosage forms intended for spatial and temporal drug release, especially enteric release, colon targeting and circadian controlled drug release, etc. MUPS are advantageous over normal conventional tablets which follow the all or none effect where as MUPS assure the availability of drug at the required site or the time and maintain the concentration of drug levels as per the intention of formulation [7-9].

In GRDDS (gastro-retentive drug delivery systems), the main aim is to maintain the drug in the stomach or upper GIT for the required period of time. In the floating type of GRDDS the particles will float on the gastric fluids for a definite period and the drug will be released at the proximity of the absorption window for the drug. A MUPS based floating drug delivery system was developed for Dipyridamole with the help of water soluble excipients like lactose, mannitol, which dissolve in aqueous gastric medium and the porous matrix provides buoyancy for the dosage form and functional polymers ethyl cellulose and Eudragit $\mathrm{NE} 30 \mathrm{D}^{\circ}$ which help in the prolonged drug release up to $12 \mathrm{~h} \mathrm{[10].} \mathrm{In}$ another study of Zolpidem tartrate floating pellets, the two functional coatings were sprayed on drug layered sugar spheres. The inner effervescent layer containing sodium bicarbonate (12\% weight gain on drug layered spheres) which was plasticized into HPMC (hydroxyl propyl methyl cellulose) with the help of PEG (poly ethylene glycol 6000 (10\% weight of HPMC weight) providing the floating ability for the system [11]. A study of bio-adhesive GRDDS was reported by Zhanga et al., 2016 in which Ofloxacin bio -adhesive system was formulated with the help of Carbomer ${ }^{\circledR}$ 934P. In this formulation release was retarded by a mixture of polymers Surelease ${ }^{\oplus}$ E-7-10940 and Eudragit $\mathrm{NE} 30 \mathrm{D}^{\circ}$ in 2:2 ratio and weight gain of functional polymers was $15 \%$ of the core pelletscoating [12].

The premature drug release in the stomach may degrade drugs which are acid labile and some molecules may be potent gastric irritants [13]. The enteric coatings can be performed on the drug-layered pellets by using anionic polymers of methacrylates and methacrylic acid like Eudragit L30D ${ }^{\circledR} 55$ (dissolves at $\mathrm{pH}>5.5$ ) or Eudragit FS30D ${ }^{\circledR}$ (dissolves at $\mathrm{pH}>7$ ) which prevent the drug release in the stomach and extend the drug release for the rest of the period. In a study reported by Rok et al., 2011 enteric release coting was performed with Eudragit L30D 55 (14-25\% weight gain on core pellets) with a plasticizer combination of triethyl citrate (TEC) (10-20\% weight of dry polymer [14]. Polymers like Eudragit $\mathrm{L} 100^{\circ}$ can be used for targeted release in colon area for drugs like celecoxib as these polymeric coating dissolves in $\mathrm{pH}$ above 6 [15]. These specific kinds of coatings enable the control over the drug release in specific regions that adds more therapeutic value to the treatment. Moreover, in combinations of 2 or more drugs MUPS provide an advantage of maintaining different time profiles for the release of different drugs which provides a better option for combinatorial formulations. Metformin has a lower half-life of $4 \mathrm{~h}$ compared to Sitagliptin phosphate (half-life of $12.4 \mathrm{~h}$ ). To develop a formulation for sustained drug delivery up to $12 \mathrm{~h}$, metformin was formulated as enteric coated, sustained releasing part where as Sitagliptin phosphate was incorporated as IR pellets. This combination provided a sustained release without any dose dumping for this combination [16]. Circadian timing of drug release is the critical factor in patient survival in severe conditions like asthma and angina pectoris. In these conditions, drug release should be pulsatile and untimely release can be fatal which makes MUPS a potential options for this kind of delivery systems [17]. Such example is Isosorbide 5 mono-nitrate coated micro crystalline cellulose pellets and these pellets were further coated with Eudragit NE
$30 \mathrm{D}^{\circ}$ (at 8,13 and $15 \%$ weight gain of polymer) to maintain a lag period of $4 \mathrm{~h}$ before drug release and the drug release was extended up to 10 h) [18]. This pulsatile release of the drug can be a crucial tool in the treatment of heart patients in whom the frequency of attack is higher between midnight to early in the morning [19].

\section{Technologies suitable to MUPS and process constraints}

The formulation and process issues like formation of a homogeneous film on pellet and further coatings need the optimization of many parameters, which depends on polymer, plasticizer, desired release profiles, the amount of the polymeric coating coated and compression behavior of pellets. The integrity of the film can be modified by choosing right polymer or plasticizer. In a reported study acetyl salicylic acid and indomethacin pellets coated with Eudragit L30D $^{\oplus} 55$ shown compression induced cracks when exposed to simulated gastric fluid and the problem was solved by adding another flexible polymer Eudragit ${ }^{\dagger}$ NE30D [20]. Similar kind of results were published for Lansprazole pellets where Eudragit ${ }^{\circledR}$ L30D55: Eudragit ${ }^{\star}$ NE30D ratio was maintained at 9:1 ratio and triethyl citrate (TEC) was incorporated as a plasticizer at $20 \% \mathrm{w} / \mathrm{w}$ concentration [21]. The physico-chemical properties of the plasticizer are also very crucial as they can affect the drug release. The plasticizer which forms an integral part of functional coating controls the elasticity and permeability of the polymeric layer on the core pellets. The reports suggest that the amount of verapamil hydrochloride released varied from the MUPS which have a Kollicoat ${ }^{\circledR}$ SR 30D as a functional polymer and triethyl citrate (TEC), dibutyl sebacate (DBS) and propylene glycol as plasticizers at $10 \% \mathrm{w} / \mathrm{w}$ proportion. The drug diffused out with higher pace in propylene glycol based formulations, whereas diffusion was slow in the case of TEC and DBS. This behavior can be attributed because of the lower aqueous solubility of TEC and DBS [22]. Table 1 includes some examples of approved, marketed products by USFDA [23].

There are some technologies other than fluid bed granulation were reported to produce MUPS. These includes, wet granulation followed by extrusion and spheronisation [24], hot melt extrusion [25] etc. The other important factor is the compression of MUPS into tablets where the integrity of film should not be damaged. The particles are more prone to damage in tablet die during compression, and smaller particle size helps to avoid the damage to the coat as the particles hides in the porous matrix of excipients [16]. One more strategy to avoid fracture during compression is the incorporation of cushioning agents like PEG, glyceryl behenate which deform on compression and porous grades of excipients like MCC 200, MCC KG-802 [26-28]. Recently prilling was reported as a technique to produce MUPS by Vervaeck et al., 2014. In this study lipids [stearic acid/behenic acid) were mixed with PEG and the mixture is in a molten state, pressurized through a nozzle with needle to form droplets [28].

\section{Conclusion}

MUPS offer many advantages in terms of drug delivery and stability of dosage forms. Main constrains in formulation and process are to be balanced to get a desired release profile. Selection of polymers, plasticizer, and optimization of process conditions are crucial in the coating process. In case of compression of MUPS into tablet, the ratio of pellets and other excipients, incorporation of cushioning agents and compression force are the key factors to be focused. Selection of appropriate excipients and optimization of processing conditions is vital in the formulation of MUPS and a balance between all these factors could make MUPS a potential drug delivery option for a variety of molecules. 
Citation: Kallakunta VR, Sarabu S, Tiwari RV (2017) Multiple Unit Particle Systems (MUPS), a Versatile Strategy for Controlled Drug Delivery: Focus on Formulation and Process Concerns. J Formul Sci Bioavailab 1: 106.

Page 3 of 3

\begin{tabular}{|c|c|c|c|c|c|}
\hline Brand Name & Drug & Manufacturer & Dosage form & Description & Year of Approval \\
\hline PRILOSEC ${ }^{\circledR}$ & $\begin{array}{l}\text { Omeprazole Magnesium } \\
\text { Eq } 20 \mathrm{mg} \text { of base }\end{array}$ & AstraZeneca Pharmaceuticals Lp & Tablets & $\begin{array}{l}\text { Delayed release dosage } \\
\text { form }\end{array}$ & 2003 \\
\hline ORACEA ${ }^{\mathrm{TM}}$ & Doxycycline-40 mg & Galderma Laboratories Lp & Capsules & $\begin{array}{l}\text { Delayed release dosage } \\
\text { form }\end{array}$ & 2006 \\
\hline NAPRELAN ${ }^{\circledR}$ & Naproxen sodium $750 \mathrm{mg}$ & Alvogen Malta Operations Ltd & $\begin{array}{l}\text { Tablets (IPDAS }^{\circledR} \text { - } \\
\text { Intestinal protective drug } \\
\text { absorption system) }\end{array}$ & $\begin{array}{l}\text { Rapidly disintegrating } \\
\text { tablet system combining } \\
\text { an IR component and a } \\
\text { SR component of micro } \\
\text { particles }\end{array}$ & 1996 \\
\hline TOPROL-XL ${ }^{\circledR}$ & $\begin{array}{l}\text { Metoprolol succinate } \\
\text { 200mg }\end{array}$ & AstraZeneca Pharmaceuticals $L p$ & Tablets & Extended Release & 1992 \\
\hline CLARINEX-D ${ }^{\circledR} 24$ HOUR & $\begin{array}{l}\text { Desloratidine- } 5 \mathrm{mg} \\
\text { and Pseudoephedrine } \\
\text { sulphate }-240 \mathrm{mg}\end{array}$ & Merck Sharp and Dohme Corp & Tablets & Extended release tablets & 2005 \\
\hline NEXIUM $^{\circledR}$ & $\begin{array}{l}\text { Esomeprazole } \\
\text { Magnesium Eq to } 40 \mathrm{mg} \\
\text { of base }\end{array}$ & AstraZeneca Pharmaceuticals Lp & Capsule & Delayed release pellets & 2001 \\
\hline PREVACID ${ }^{\circledR}$ & Lansoprazole- 30 mg & Takeda Pharmaceuticals USA Inc. & Tablet & $\begin{array}{l}\text { Delayed release, orally } \\
\text { disintegrating }\end{array}$ & 2002 \\
\hline PREVACID 24 HR $^{\circledR}$ & Lansoprazole- $15 \mathrm{mg}$ & $\begin{array}{l}\text { GlaxoSmithKline Consumer } \\
\text { Healthcare }\end{array}$ & Capsule & Delayed release pellets & 2009 \\
\hline
\end{tabular}

Table 1: Some examples of marketed products of MUPS approved by USFDA.

\section{References}

1. Collett J, Moreton C (2001) Modified-release per oral dosage forms. In: Aulton ME (ed.) Pharmaceuticals: the Science of Dosage Form Design, Churchil Livingstone, New York: 289-305.

2. Clarke GM, Newton JM, Short MD (1995) Comparative gastrointestinal transit of pellet system of varying density. Int J Pharm 114: 1-11

3. Aulton ME, Dyer AM, Khan KA (1954) The strength and compaction of millispheres: The design of controlled-release drug delivery system for ibuprofen in a form of a tablet comprising compacted polymer-coated millispheres. Drug Dev Ind Pharm 20: 3069-3104.

4. Celik M (1994) Compaction of multiparticulate oral dosage form. In: GhebreSellassie I (ed.) Multiparticulate Oral Drug Delivery. Marcel Dekker, New York: 181-215.

5. Illoanusi ND, Schwartz JB (1998) The effect of wax on compaction of micro crystalline cellulose beads by extrusion and spheronisation. Drug Dev Ind Pharm 24: 37-44.

6. Santos H, Veiga F, Pina ME, Sousa JJ (2004) Compaction, compression and drug release characteristics of xanthan gum pellets of different composition. Eur J Pharm Sci. 21: 271-281.

7. Davis SSR, Khosia CG, Wilson N, Washington (1987) Gastrointestinal transit of controlled release pellet formulation of tiaprofenic acid and the effect of food. Int J Pharm 35: 253-258

8. Davis SS (2005) Formulation strategies for absorption windows. Drug Discov Today 4: 249.

9. Streubel J, Siepmann R, Bodmeier (2006) Drug delivery to the upper smal intestine window using gastroretentive technologies. Curr Opin Pharmacol 6 : 501-508

10. Li Z, Xu H, Li S, Li Q, Wenji A (2014) A novel gastro-floating multiparticulate system for dipyridamole (DIP) based on a porous and low-density matrix core: In vitro and in vivo evaluation. International Journal of Pharmaceutics 461: 540-548.

11. Amrutkara PP, Chaudharib PD, Patil SB (2012) Design and in vitro evaluation of multiparticulate floating drug delivery system of zolpidem tartarate. Colloids and Surfaces B: Biointerfaces 89: 182-187.

12. Zhanga C, Tangc J, Liub D, Lia X, Chenga $L$ (2016) Design and evaluation of an innovative floating and bioadhesive multiparticulate drug delivery system based on hollow structure. International Journal of Pharmaceutics 503: 41-55.

13. Decheshe JP, Delattre L (1996) A new enteric tablet of acetylsalicylicacid: bio pharmaceutical aspects. Int J Pharm 34: 257-262.

14. Dreu R, Ilić I, Srčič S (2011) Development of a multiple-unit tablet containing enteric-coated pellets Pharmaceutical Development and Technology 16: 118-126.

15. Sinha VR, Aggarwal A, Srivastava S, Goel H (2010) Influence of operational variables in multi-particulate delayed release systems forcolon-targeted drug delivery of celecoxib using extrusion spheronization. Asian Journal of Pharmaceutics.

16. Agrawal S, Joshi K, Gaud R (2011) Formulation development of multi unit particulate system (MUPS) for anti-diabetic drugs. Asian journal of pharmaceutical Sciences 11: 77-78.

17. Liu Q, Gong Y, Shi Y, Jiang L, Zheng C (2013) A Novel Multi-Unit Tablet for Treating Circadian Rhythm Diseases. AAPS Pharm SciTech 14: 2.

18. Liu Q, Gong Y, Shi Y, Jiang L, Zheng C (2013) A Novel Multi-Unit Tablet for Treating Circadian Rhythm Diseases. AAPS Pharm Sci Tech 14: 861-869.

19. Cassano GB, Maggini C, Guazzelli M (1981) Nocturnal angina and sleep. Prog Neur Psychopharmacol 5: 99-104.

20. Lehmann K, Petereit HU, Dreher D (1994) Fast disintegrating controlledrelease tablets from coated particles. Drugs Made Ger 37: 53-60.

21. Shimizu T, Nakano Y, Morimoto B, Tabata T, Hamaguchi N (2003) Formulation study for Lansoprazole fast-disintegrating tablet. I. Effect of compression on dissolution behavior. Chem Pharm Bull 5: 942-947.

22. Lippold BC, Pages RM (2001) Film formation, reproducibility of production and curing with respect to release stability functional coatings from aqueous polymer dispersion. Pharmazie 56: 5-17.

23. Mehtaa S, Beerb TD, Remona JP, Vervaeta C (2012) Effect of disintegrants on the properties of multiparticulate tablets comprising starch pellets and excipient granules. International Journal of Pharmaceutics 422: 310-317.

24. Malodea VN, Paradkarb A, Devarajana PV (2015) Controlled release floating multiparticulates of metoprolol succinate by hot melt extrusion. International Journal of Pharmaceutics 491: 345-351.

25. Harsey JA, Cole ET, Reese JE (1973) Proceedings of the First International Conference on the Compaction and consolidation of particulate matter, London.

26. Illoanusi ND, Schwartz JB (1998) The effect of wax on compaction of micro crystalline cellulose beads by extrusion and spheronisation, Drug Dev Ind Pharm 24: 37-44.

27. Asahi Chemical Corp, Yaginuma Y, Yoshida N (2010) Process for production of tablets containing both crystalline cellulose and granules: WO, WO 2009/028487 A1[P]. 2009-03-05.

28. Vervaeck A, Monteyne T, Saerens L, De Beer T, Remon JP (2014) Prilling as manufacturing technique for multiparticulate lipid/PEG fixed-dose combinations. European Journal of Pharmaceutics and Biopharmaceutics 88: 472-482. 